ORIGINAL ARTICLE

\title{
Prospective study of acute gastrointestinal bleeding attributable to anti-inflammatory drug ingestion in the Yorkshire region of the United Kingdom
}

\author{
C H Lim, R V Heatley
}

Postgrad Med J 2005;81:252-254. doi: 10.1136/pgmj.2004.024885

See end of article for authors' affiliations

......................

Correspondence to: Dr C H Lim, Department of Gastroenterology, Room 190A Clarendon Wing, The General Infirmary at Leeds, Great George Street, Leeds LSI 3EX, UK; ch.lim@virgin.net

Submitted 1 June 2004 Accepted 17 July 2004

\begin{abstract}
Objective: To assess the general use of all non-steroidal anti-inflammatory drugs (NSAID) and their relation to upper gastrointestinal bleeding in view of National Institute for Clinical Excellence guidelines published in July 2001 in the UK.

Methods: Cross sectional study on all patients who were referred for endoscopy for suspected upper gastrointestinal bleeding in six hospitals in Yorkshire region of the UK.

Results: One hundred and sixty three patients presented for endoscopy for suspected upper gastrointestinal bleeding, 43 patients were taking at least one ulcerogenic drug, and 120 were not. The mean age difference between these two groups was eight years $(p<0.01)$. The absolute difference between the proportion of patients with peptic ulcer disease/erosion (PUD) in NSAID with/without aspirin group and no ulcerogenic drug group was $31 \%(p=0.02)$. The difference between the proportion of PUD in cyclo-oxygenase 2 with/without aspirin group and no ulcerogenic drug group was $30 \%(p=0.1)$. The overall 30 days mortality rate was $14.1 \%$.

Conclusions: Elderly patients are being inappropriately prescribed conventional NSAIDs. NSAIDs with or without aspirin use are still associated with a significant risk of upper gastrointestinal bleeding in the era of cyclo-oxygenase 2 selective agents. Substitution with cyclo-oxygenase 2 selective NSAIDs is not without risk of upper gastrointestinal bleeding.
\end{abstract}

$\mathrm{N}$ on-steroidal anti-inflammatory drugs (NSAIDs) are undoubtedly the most widely used symptomatic remedies for common rheumatic disorders. The most commonly seen and serious side effects involve damage to the upper gastrointestinal tract. New anti-inflammatory agents with more specific inhibitory effects on cyclooxygenase 2 (COX-2) pathways have been developed, in the hope of reducing some, if not all, of the gastrointestinal toxicity of anti-inflammatory drugs. However, it has been questioned whether this is likely to be the case in practice. Gastrointestinal toxicity from NSAIDs is common, with hospitalisation of an estimated 107000 patients and death of 16500 patients each year in the USA. ${ }^{2}$ The reported rates for gastrointestinal disorder in UK was 53-62 per 100000 COX-2 selective NSAIDs prescriptions. ${ }^{3}$

COX-2 selective NSAIDs have now been available in the UK for several years and are recommended by the National Institute for Clinical Excellence (NICE) in patients who may be "high risk" for serious gastrointestinal toxicity. ${ }^{4}$ This high risk group includes age 65 or more, history of upper gastrointestinal haemorrhage, and serious comorbidities. Currently, there are few data available on the general use of these agents, or on their current place in reducing gastrointestinal toxic effects of anti-inflammatory agents. To assess this in our healthcare region, we have conducted a prospective study of acute admissions for gastrointestinal bleeding in our geographical locality, relating this particularly to recent anti-inflammatory drug use.

\section{METHODS}

\section{Patients and definitions}

We conducted an endoscopy based prospective cross-sectional study in six hospitals (three teaching and three district hospitals) in the county of Yorkshire. These six hospitals provide secondary care services to an estimated population of
1.6 million. ${ }^{5}$ We collected the data (anonymous) prospectively for all patients who were referred for endoscopy for suspected upper gastrointestinal haemorrhage for two months from October 2002 to December 2002. The standard definition for suspected upper gastrointestinal haemorrhage was used to select our sample. ${ }^{6}$ Patients were included in the study if they were aged 16 years or older and had clinical evidence of acute upper gastrointestinal bleeding on admission, a history of having experienced such a bleed up to 10 days before the date of admission, or clinical evidence of acute upper gastrointestinal bleeding while an established inpatient for any other reason.

We chose endoscopy based data collection because we were interested in the potential high risk groups who had experienced significant bleeds. The high risk group was defined by Rockall et al with age, comorbidities, shock, and endoscopic findings as independent risk factors. ${ }^{7}$ All hospitals were asked to search in their endoscopy report database at the end of the study to ensure that all data collection was complete. The prescribing data for the studied region were obtained from IMS Health. These data were drawn from an analysis of $97 \%$ of the invoices issued by wholesalers and manufacturers to retail pharmacies within the catchment postcodes for the six hospitals.

The primary observational measure in this study was the proportion of patients who were endoscoped for suspected upper gastrointestinal haemorrhage with peptic ulcer or erosion in each ulcerogenic drug cohort (NSAID, aspirin or COX-2 selective NSAID). The secondary measures included the endoscopic diagnoses and 30 day mortality. We used

Abbreviations: NSAID, non-steroidal anti-inflammatory drug; COX-2, cyclo-oxygenase 2; NICE, National Institute for Clinical Excellence; PUD, peptic ulcer disease 


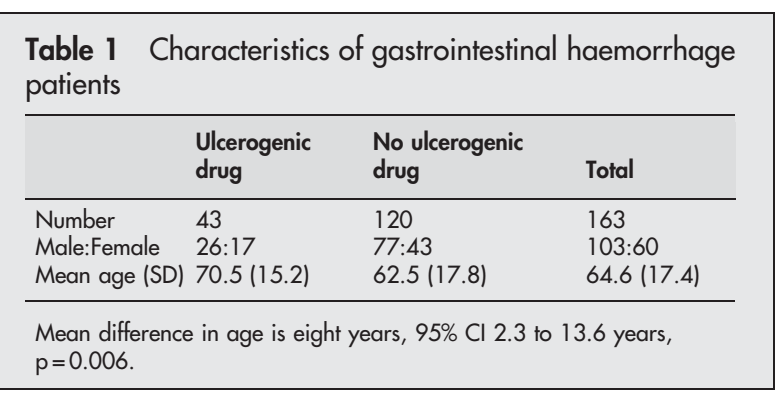

independent $t$ test for continuous data and $\chi^{2}$ test for categorical data.

\section{RESULTS}

\section{Study sample}

One hundred and sixty three patients had upper gastrointestinal endoscopy for suspected upper gastrointestinal haemorrhage within the two month study period. One hundred and thirty three patients $(82 \%)$ were from the three teaching hospitals. Forty three $(26 \%)$ patients were taking at least one potential ulcerogenic drug at admission. Table 1 shows the patient characteristics. The overall mean age was 64.6 years with a male predominance of $63 \%$ (103/163). The mean age for patients who were taking ulcerogenic drugs was on average eight years older (95\% CI 2.3 to 13.6 years) than those who were not. This difference was significant $(\mathrm{p}=0.006)$ using independent $t$ test.

\section{Outcome}

Table 2 shows the proportion for upper gastrointestinal haemorrhage in each drug cohort with the endoscopic diagnoses, history for peptic ulcer disease (PUD), and concomitant proton pump inhibitor use. The concomitant use of aspirin with NSAIDs or COX-2 selective NSAIDs were combined in the same cohort because the number involved was small (two in each cohort) and unlikely to influence the overall result. The absolute difference in proportion of PUD and peptic erosion for all NSAIDs and/or aspirin use compared with no ulcerogenic drug was $18 \%$. This was statistically significant and the 95\% confidence interval does suggest all NSAIDs are probably more harmful. Most patients who were taking ulcerogenic drugs were taking either aspirin or a non-selective NSAID. Non-selective NSAIDs were associated with a greater number of PUD and peptic erosion bleeds than aspirin alone. COX-2 selective NSAIDs were also associated with bleeding PUD but the number of patients presenting during our study period were less than those taking non-selective NSAIDs. Table 3 shows the endoscopic diagnoses for all suspected upper gastrointestinal haemorrhage. Thirty nine per cent of all suspected upper gastrointestinal haemorrhage was associated with PUD. The overall 30 day mortality rate was $14.1 \%$.
Table 3 Endoscopic diagnoses for all suspected upper gastrointestinal haemorrhage

\begin{tabular}{llc}
\hline Diagnosis & Frequency & Percentage \\
\hline Normal & 24 & 14.7 \\
Erosive disease & 17 & 10.4 \\
Mallory Weiss & 9 & 5.5 \\
Oesophagitis & 15 & 9.2 \\
Gastric ulcer & 28 & 17.2 \\
Duodenal ulcer & 36 & 22.1 \\
Varices & 19 & 11.7 \\
Others & 15 & 9.2 \\
Total & 163 & 100.0 \\
\hline & & \\
\end{tabular}

The mean number of monthly packs of NSAID prescribed in the geographical regions studied during the study period was 44683 compared with 11277 for COX-2 selective NSAIDs (4:1 ratio). The non-selective NSAIDs included were diclofenac, ibuprofen, naproxen, misoprostol, meloxicam, indometacin, mefenamic acid, piroxicam, etodolac, cycrimine, nabumetone, ceclofenac, ketoprofen, tiaprofenic acid, flurbiprofen, fenbufen, benorilate, sulindac, tenoxicam, piroxicam, azapropazone, acemetacin, and fenoprofen. The COX-2 selective NSAIDs included were rofecoxib, celecoxib, etoricoxib, and parecoxib. Therefore, the apparent lower number of patients taking COX-2 selective NSAID presenting with suspected upper gastrointestinal haemorrhage may reflect the prescription data.

\section{DISCUSSION}

There has been a general decline in Britain for hospital admissions and mortality rate for PUD from the 1950s to 1980s. ${ }^{8}$ The converse trend is true for perforated peptic ulcer and the mortality from duodenal ulcer increased among older women from the 1970s to 1980s. ${ }^{8}$ The discovery of ever more effective therapeutic agents and the benefit of Helicobacter pylori eradication in relation to PUD has led to an expectation that the incidence of PUD is in decline. ${ }^{9}$ However, a recent study showed that the hospital admission rates in England for upper gastrointestinal haemorrhage have increased among older patients from 1989 to $1998 .{ }^{8}$ The result of our study with a mean admission age of 64.6 years is consistent with this trend. Despite NICE guidelines, we must assume from our data than many "high risk" patients may not be prescribed NSAID totally appropriately. Our findings, as they are seen in several hospitals, can probably be extrapolated throughout the UK but it would be interesting to know if NSAID and COX-2 selective NSAID prescribing varies significantly in different geographical regions. There are scarce published data showing the extent of COX-2 selective NSAID prescribing in the UK and the appropriateness of patient selection for anti-inflammatory drug use.

Table 2 Proportion for upper gastrointestinal haemorrhage in each drug cohort

\begin{tabular}{|c|c|c|c|c|c|c|}
\hline Drugs & $\begin{array}{l}\text { Suspected upper } \\
\text { gastrointestinal } \\
\text { haemorrhage }\end{array}$ & $\begin{array}{l}\text { Peptic ulcer } \\
\text { disease }\end{array}$ & $\begin{array}{l}\text { Peptic } \\
\text { erosion* }\end{array}$ & $\begin{array}{l}\text { Absolute difference between } \\
\text { proportion }(95 \% \mathrm{Cl}) \dagger\end{array}$ & PUD history & $\begin{array}{l}\text { Concomitant proton } \\
\text { pump inhibitor }\end{array}$ \\
\hline NSAID +/- aspirin & 17 & 11 & 2 & $31 \%(6 \% \text { to } 56 \%)^{1}$ & 2 & 3 \\
\hline Aspirin & 18 & 3 & 5 & $-1 \%(-26 \% \text { to } 24 \%)^{2}$ & 2 & 2 \\
\hline COX-2 +/- aspirin & 8 & 6 & 0 & $30 \%(-6 \% \text { to } 66 \%)^{3}$ & $\overline{1}$ & 0 \\
\hline Sub-total & 43 & $20+$ & $7+$ & $18 \%(1 \% \text { to } 35 \%)^{4}$ & 5 & $5(11 \%)$ \\
\hline No ulcer related drug & 120 & $44 \dagger$ & $10 \dagger$ & $0 \%$ & $\mathrm{~N} / \mathrm{A}$ & $15(13 \%)$ \\
\hline Total & 163 & 64 & $17 \ddagger$ & & $\mathrm{N} / \mathrm{A}$ & 20 \\
\hline
\end{tabular}

*An erosion if the lesion is small ( $<5 \mathrm{~mm}$ diameter) and shallow with no sign of scarring. TThe difference between the proportion of peptic ulcer disease and peptic erosion in each drug cohort and control group (no ulcer related drug). $¥$ Five also had reflux oesophagitis. ${ }^{1} p=0.02 ;{ }^{2} p=0.92 ;{ }^{3} p=0.10 ;{ }^{4} p=0.05$. 
Our overall mortality rate was $14 \%$, which is at the higher end of the expected rate but is comparable to UK national audit. ${ }^{10}$ This mortality rate reflects the sample selection of our patients being older people often with significant morbidity. Moreover, most deaths were as a result of unrelated complications in elderly patients with significant comorbidities.

This study shows the relation of ulcerogenic drugs to upper gastrointestinal haemorrhage in daily clinical practice at the current time in different hospital environments. It does not directly address the question of whether COX-2 selective NSAIDs are safer than NSAIDs as no direct comparisons were made. This has been shown by a number of randomised controlled trials. ${ }^{11-13}$ It does however show that NSAID, aspirin, or COX-2 selective NSAID is associated with more than a quarter of all patients with suspected significant gastrointestinal haemorrhage giving comparable figures to those determined by others. ${ }^{14}$ The association between COX-2 selective NSAIDs and peptic adverse event was not statistically significant possibly because of the small number of patients in this group. This suggests that despite NICE and Committee on Safety of Medicine guidance, the prescription pattern for NSAIDs has not greatly changed. ${ }^{415}$ We accept that our selection method will not include all patients with suspected upper gastrointestinal haemorrhage in particular those who were not referred for endoscopy. However, these patients are likely to be younger with little or no comorbidity and unlikely to suffer from any significant adverse outcome.

There is little work on following up whether guidelines influence clinical practice. In the case of NSAID prescribing in our geographical region it is clear that not all high risk patients are being treated appropriately. Further research is needed to identify these reasons if we are going to have an impact on reducing serious gastrointestinal complications of NSAIDs. It is also clear that it is not always entirely possible to predict those patients at highest risk of gastrointestinal bleeding on the basis of their history.

Our results suggest that NSAID use is still significantly associated with gastrointestinal haemorrhage in the era of COX-2 selective NSAIDs. This is in line with the latest reminder from Committee on Safety of Medicine on gastrointestinal toxicity of NSAIDs. ${ }^{15}$ Poor adoption of the NICE guideline is one issue that will need tackling if we are to change the trend of hospital admission rates for upper gastrointestinal haemorrhage. It is apparent that high risk patients remain at risk of upper gastrointestinal haemorrhage even if COX-2 selective NSAID drugs are prescribed and patients may need to be vigilant.

\section{ACKNOWLEDGEMENTS}

We thank all the staff in the following endoscopy units for their participation in this study: Str Radcliffe (Scarborough Hospital), Str Jackson (York District Hospital), Str D Moate (Pontefract), Str R Walker (Bradford Royal Infirmary), Str J Bowen (St James University
Hospital, Leeds), Str L Murphy (Leeds General Infirmary). We also thank IMS Health, London for providing us with the prescribing data in our region and Pfizer Pharmaceuticals for research funding. Pfizer pharmaceuticals had no further input in this study and data were collected and results analysed independently of Pfizer.

\section{Authors' affiliations}

C H Lim, Department of Gastroenterology, The General Infirmary at Leeds, UK

R V Heatley, Department of Gastroenterology, St James's University Hospital, Leeds, UK

Conflict of interests: CH Lim has received a travel grant from Pfizer Pharmaceuticals. RV Heatley has received research funding, consultancy fees, financial support for attendance at scientific meetings and speaker's fees from a number of companies with interests in this field, including Abbott Laboratories, AstraZeneca, Eisai, Glaxo Smith Kline, Janssen-Cilag, M.S.D., Reckitt BencKiser Healthcare, Sanofi-Synthelabo, and Wyeth Laboratories.

\section{REFERENCES}

1 Peterson WL, Cryer B. COX-1-sparing NSAIDs - is the enthusiasm justified? JAMA 1999;282:1961-3

2 Wolfe MM, Lichtenstein DR, Singh G. Gastrointestinal toxicity of nonsteroidal antiinflammatory drugs. N Engl J Med 1999;340:1888-99.

3 MHRA/CSM. Non-steroids anti-inflammatory drugs (NSAIDs) and gastrointestinal (GI) safety. Current Problems in Pharmacovigilance 2002;28:5

4 National Institute for Clinical Excellence. Guidance on the use of cyclooxygenase (Cox) II selective inhibitors, celecoxib, rofecoxib, meloxicam and etodolac for osteoarthritis and rheumatoid arthritis. London: National Institute for Clinical Excellence, 2001:1-18.

5 Office of National Statistics. Census 2001. London: Office of National Statistics, 2003.

6 Rockall TA, Logan RF, Devlin HB, et al. Incidence of and mortality from acute upper gastrointestinal haemorrhage in the United Kingdom. Steering committee and members of the national audit of acute upper gastrointestinal haemorrhage. BMJ 1995;311:222-6.

7 Rockall TA, Logan RF, Devlin HB, et al. Selection of patients for early discharge or outpatient care after acute upper gastrointestinal haemorrhage. National audit of acute upper gastrointestinal haemorrhage. Lancet 1996;347:1 138-40

8 Higham J, Kang JY, Majeed A. Recent trends in admissions and mortality due to peptic ulcer in England: increasing frequency of haemorrhage among older subjects. Gut 2002;50:460-4.

9 Spiro HM. Peptic ulcer: Moynihan's or Marshall's disease? Lancet 1998:352:645-6.

10 Rockall TA, Logan RF, Devlin HB, et al. Variation in outcome after acute upper gastrointestinal haemorrhage. The national audit of acute upper gastrointestinal haemorrhage. Lancet 1995;346:346-50.

11 Langman MJ, Jensen DM, Watson DJ, et al. Adverse upper gastrointestinal effects of rofecoxib compared with NSAIDs. JAMA 1999;282:1929-33.

12 Bombardier C, Laine L, Reicin A, et al. Comparison of upper gastrointestinal toxicity of rofecoxib and naproxen in patients with rheumatoid arthritis. VIGOR Study Group. N Engl J Med 2000;343:1520-8.

13 Silverstein FE, Faich G, Goldstein JL, et al. Gastrointestinal toxicity with celecoxib vs nonsteroidal anti-inflammatory drugs for osteoarthritis and rheumatoid arthritis: the CLASS study: a randomized controlled trial. Celecoxib long-term arthritis safety study. JAMA 2000;284:1247-55.

14 Rockall TA, Logan RF, Devlin HB, et al. Risk assessment after acute upper gastrointestinal haemorrhage. Gut 1996;38:316-21.

15 MHRA/CSM. Reminder: gastrointestinal toxicity of NSAID. Current Problems in Pharmacovigilance 2003;29:8-9. 